\title{
Percepção Ambiental e Estudantes de Enfermagem
}

\author{
Environmental PerceptionandNursingStudents
}

\author{
Ana Emília Rosa Campos', Marcelo Cesar Lima Peres" e Bruna dos Reis Pereira"II
}

\begin{abstract}
RESUMO
A indissociabilidade entre a saúde e o meio, é essencial para melhor atuação dos enfermeiros, ainda vista na formação como uma temática periférica. A maneira como o aluno percebe o meio ambiente indica como será sua atuação em relação ao cuidado com o meio ambiente e seus impactos na saúde das populações. A forma como o profissional cuida desse meio depende da percepção ambiental que tem do mesmo. Trata se de um estudo de caso, do tipo descritivo com abordagem qualitativa. Objetivo geral: Identificara forma que os alunos de enfermagem percebem o meio ambiente. Foi utilizada a entrevista semiestruturada para coleta de dados. Os resultados indicaram que a percepção ambiental predominante é reducionista, 0 que pode impactar em suas atuações e responsabilidades sobre este meio. É necessário ultrapassar a percepção reducionista, desde a graduaçãode enfermagem sensibilizando os alunos para agirem de forma responsável com o meio em que vivem e suas ações de promoção a saúde humana.
\end{abstract}

Palavras-chave: Planejamento ambiental;Estudantes de Enfermagem; Saúde ambiental

\section{ABSTRACT}

The inseparability between health and the environment is essential for the better performance of nurses, still seen in training as a peripheral theme. The way the student perceives the environment indicates how it will act in relation to care for the environment and its impacts on the health of the population. The way the professional takes care of this environment depends on the environmental perception that it has of it. This is a descriptive case study with a qualitative approach. Overall objective: Identify the way nursing students perceive the environment. The semi-structured interview for data collection was used. The results indicated that the predominant environmental perception is reductionist, which may impact on its actions and responsibilities on this medium. It is necessary to overcome the reductionist perception, from the nursing graduation, sensitizing students to act responsibly with the environment in which they live and their actions to promote human health.

Keywords: Environmental planning; Nursing Students; Environmental health

\section{INTRODUÇÃO}

Compreender a correlação existente entre a saúde e o meio ambiente vem se tornando nas últimas décadas fundamental para a melhoria da qualidade de vida das populaçóes. O meio ambiente por exercer influencias diretas e indiretas no processo saúde-doença, podepromover ou criar condiçóes nocivas para a saúde dos indivíduos, tendo em vista que este processo depende das variáveis ambientais (BRUZOS et al.., 2011; PERES et al., 2016).

A percepção dessa indissociabilidade entre saúde e meio, é o que servirá como base para as açóes dos profissionais de saúde. Para tanto, os enfermeiros, precisam integrar a dimensão ambiental em sua formação e em suas práticas, pois somente com uma visão integrada de meio ambiente/saúde é possível estabelecer uma relação complexa de cuidados, que visem à promoção da sustentabilidade ambiental (BACKES et al.., 2011;BRUZOS et al.., 2011).

'Professor de graduação e pós - graduação, Universidade Católica do Salvador, BA, Brasil. aerc25@gmail.com

"Doutor em Ecologia, Universidade Católica do Salavador, Salvador, BA, Brasil.marcelo.peres@ucsal.br

"'Graduanda de Enefermagem,.Universidade Católica do Salvador, Salavador, BA, Brasil. bruna.reis.pereira@hotmail.com 
Como apontam Evangelista et al.. (2017), o trabalhador de saúde deve atuar na prevençáo e controle de endemias, e por este motivo, é fundamental que tenham uma percepção mais ampla da relação meio/ saúde.

Diversos autores salientam a importânciaemdebater sobre a interface saúde e meio ambiente na formação,pois, essa iniciativa visa atitudes profissionais ambientalmente responsáveis, possibilitando assim, que o sujeito possa perceber-se afetado pela atual problemática ambiental. É necessário ultrapassar as práticas assistencialistas da graduação de enfermagem para umaformação mais voltada diante das questóes ambientais, comatitudes inovadoras que possam ser capazes de problematizar as diferentes situaçóes, ou entornos, nos quais o ser humano está inserido(BACKES et al., 2011; BRUZOS et al., 2011; PERES et al.. 2014).

Estudos sobre a percepção ambiental indicam a forma como os sujeitos agem e reagem sobre o meio em que vivem. As análises sobre percepção ambiental forneceminformações relevantes sobre relações homem/ meio ambiente, como cada indivíduo percebe,reage e responde diferentemente frente às açóes sobre o meio (KRZYSCZAK, 2016).

Dessa forma é fundamental que os profissionais da saúde, entre eles, os enfermeiros tenham uma percepção mais ampla da interface meio/saúde, pois a mesma terá influencia direta na sua conduta em relaçáo ao meio ambiente.Dentro desse contexto, esta pesquisa se propôs a conhecer a percepção ambiental dos alunos de enfermagem, apresentando como objetivo: identificar a forma que os alunos percebem o meio ambiente.

\section{METODOLOGIA}

A pesquisa utilizou uma abordagem qualitativa, do tipo descritivo, aplicando o estudo de caso como estratégia. Pelo recorte único no tempo, o delineamento do estudo foi transversal. Para Minayo (2014) a pesquisa qualitativa trabalha com o universo dos significados e o conjunto de fenômenos humanos é entendido como parte da realidade social. Aestratégia do estudo de caso, do tipo descritivo, foi utilizadapor revelar características de determinada população ou de determinado fenômeno, através da identificação, da observação, da descrição e da análise, contribuindo assim, para sua compreensão (Yin, 2005).

O local do estudo foi uma Faculdade de Enfermagem, privada,localizada na cidade do Salvador - Bahia, em que os formandos de Enfermagem (2017.1)constituíram-na população. A escolha dos alunos de Enfermagem se deu pelo fato de que os enfermeiros são os profissionais que representam o maior contingente na área da saúde e ainda por serem osque trabalham mais próximos das comunidades. Por se tratar de estudo com seres humanos, o mesmo foi submetido ao Comitê de Ética em Pesquisa (CEP) da UCSal para análise, sendo aprovado com o número 1.855.333.

A coleta de dados iniciou após o consentimento da coordenação do Curso de Enfermagem e da assinatura dos alunos no TCLE (Termo de Consentimento Livre e Esclarecido). Com o intuito de assegurar o anonimato, os nomes dos alunos foram substituídos por conceitos do Planejamento Ambiental.

Optou se por trabalhar com a entrevista semiestruturada como instrumento de coleta de dados, apresentando como questão norteadora: Qual é a sua percepção sobre o meio ambiente? As entrevistas foram realizadas pela pesquisadora principal em uma sala reservada e gravadas por meio digital de áudio com duração média de 30 minutos, transcritas na íntegra posteriormente. Comintuito de validar o instrumento, foi realizado um pré-teste com três alunos visando à adequaçáo da questão norteadora.

O universo era representado por 38 alunos. Desse total, três foram excluídos, pois participaram do pré-teste. Dos 35 restantes, o ponto de corte foi determinado pelo critério de saturaçáo de respostas, que ocorre quando é observado nacoleta de dados a obtenção de um número suficiente de sujeitos para permitir certa reincidência das informaçóes (BARDIN, 2011). No total, 18 alunos foram incluídos na amostra.

Os dados foram analisadospelo referencial de análise de conteúdo de Bardin, seguindo as três etapas:pré-análise, exploração do material,tratamento dos resultados obtidos, interpretação e discussão (Bardin, 2011; Minayo, 2007). Após a leitura exaustiva das entrevistasminuciosamente transcritas, foram captados os núcleos de sentidos, ou seja, a frequência com que os dados emergiram nos achados, suas semelhanças e diferenciaçóes.

As regras preconizadas por Bardin (2011), como a regra da exaustividade, da representatividade,da homogeneidade e da pertinência foram seguidas. Após esta etapa, os núcleos deram origem às categorias de análise, que foram interpretadas e discutidas com a literatura pertinente.

No primeiro momento da análise, foi realizada a caracterização dos participantes em relação a idade e ao sexo através de percentuais numéricos. Para as diferentes categorias de Percepçáo Ambiental foi estabelecida a representatividade numérica (percentuais) visando uma melhor visualização dos dados coletados, permitindo assim a discussão com a literatura pertinente. 


\section{ANÁLISE E DISCUSSÃO DOS RESULTADOS}

O total de participantes foi de 18 alunos de enfermagem formandos, sendo a maioria dos alunos do sexo feminino $(83,3 \%)$ e cerca de $17 \%$ do sexo masculino, com idade média de 24,8 .

Foram encontradas três subcategorias diferentes de percepção ambiental, com as seguintes representatividades numéricas (percentuais): a reducionista $(61,1 \% ; n=11)$, a socioambiental $(27,8 \% ; n=5)$ e a utilitarista $(11,1 \% ; n=2)($ Gráfico 1).

Gráfico 1 - Distribuição do tipo de Percepção ambiental dos formandos de enfermagem, Faculdade de Enfermagem, 2017

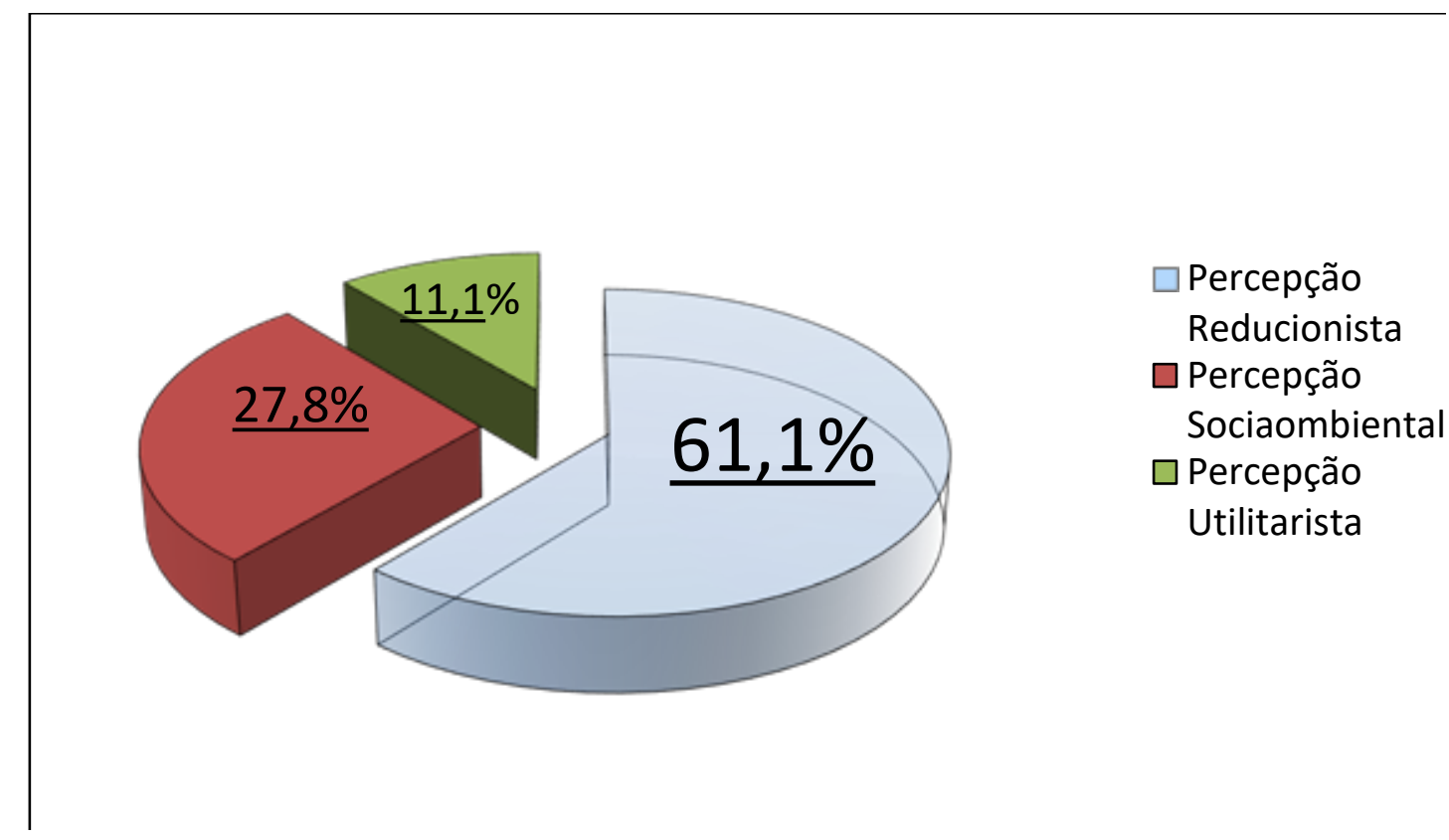

Fonte: Elaborado pelo autor, 2017

Os maiores resultados indicaram que a percepção do ambiente reducionista, representou $61,1 \%$, o que fica claro nas falas dos alunos:

É... É....o meio em que que vivemos, os animais, as plantas, o sol, planetas também? É tanta coisa né? O mundo é muito grande e tem de tudo. Fauna

Tudo o que nos cerca, a natureza em si, tudo mesmo. Tipo assim....árvore, flores, frutas, pessoas, plantação, animais, pássaros, até os insetos (rsrsrs), mar, água, cachoeira, terra, sol e ar. Conservação

A percepção socioambiental do meio apresentou um percentual de $27,8 \%$ entre os entrevistados. Os participantes falam:

(...) Acho que meio ambiente é tanto essa questão de floresta, animais, solo, águas, frio, calor e tal...é o meio em que a gente tá inserido diariamente, nossa vida e a relação com o mundo externo. Espécie

O meio ambiente para mim não é só a questão do ecossistema, e sim um ambiente de seres humanos em conjunto com animais, com flora, com fauna, com todo sistema social (...) A gente e o meio é uma coisa só. Oceano

Com o menor número de repostas, foi encontrada a percepção utilitarista do meio ambiente, 11,1\%:

(...) as formas de vida. (...). É o local onde tiramos tudo que precisamos, nosso meio de vida entendeu? Biosfera

Eu acho que tudo que está fora de nós.... (...) é a forma que temos para sobreviver no planeta terra. Ai de nós se não fosse o meio, a natureza. $\mathrm{O}$ meio é que nos fornece tudo que precisamos para sobreviver. Flora 
Outros estudos realizados na área da saúde, com a população de trabalhadores hospitalares e estudantes de saúde, inclusive com estudantes de enfermagem, também predominaram a percepção reducionista do meio assim como com os alunos deste trabalho (CAMPONOGARA et al.., 2011; PERES et al.., 2014).A percepção reducionista do meio pode ser consequência da formação recebida, que prioriza o ensino de situaçóes patológicas, em detrimento de uma visão de promoção da saúde e do cuidado com o meio ambiente.

Quando comparados aos alunos de Biologia e aos alunos do curso técnico em meio ambiente, os resultados encontrados se divergiram, sendo que os respectivos alunos nutrem uma percepção de meio mais abrangente(CARDOSO et al.., 2015; SILVA et al.., 2017).

Na pesquisa de Peres et al.. (2016) realizado com docentes de enfermagem, os resultados apontaram que o meio ambiente é percebido como causador de doenças, porém a abordagem na formaçáo profissional, ainda é superficial, evidenciando uma lacuna. Esta lacuna na formação aponta uma necessidade maior desse debate no exercício da prática do cuidado de enfermagem, que só é possível quando a percepção reducionista do meio for superada.

O percentual de $27,8 \%$ para a percepção socioambiental dos formandos no presente estudo foram mais significativos do que os obtidos, com a equipe de trabalhadores do Pronto Socorro, e trabalhadores hospitalares na pesquisa de Peres et al.. (2014). Os resultados encontrados só não foram mais significativos quando comparados aos dos alunos de Biologia e alunos do curso técnico do meio ambiente em outros estudos (CARDOSO et al.., 2015; SILVA et al.., 2017).

O baixo percentual identificado para a percepção utilitarista do meio entre os formandos de enfermagem também foram equivalentes aos estudos com alunos do curso técnico em meio ambiente, e em alunos do curso de Biologia (CARDOSO et al.., 2015; SILVA et al..., 2017).

No Brasil, propostas de reorganização do modelo de saúde pressupóem reorientar a assistência de cunho curativo, dando prioridade às intervençôes de cunho preventivo e promocional, e não mais na atuação reduzida do profissional aliviando dores e mal estar causados pelo adoecimento. Logo, a percepçáo socioambiental dos alunos possibilita a superação de práticas assistencialistas e curativas, levando à construção de equipes sensíveis e atentas às questóes ambientais e seus impactos diretos na saúde das comunidades.

A percepção reducionista do meio ambiente pode vir a impactar as açóes dos alunos enquanto enfermeiros nos seus campos de trabalho. Este tipo de concepção do meio faz com que o aluno não perceba a correlação existente entre ambiente saudável e saúde da população. Diante deste cenário se faznecessário uma formação que estimulereflexóes sobre um saber ambiental, pois cuidar da saúdeé cuidar do meio ambiente. Apenas dessa forma, é possível sustentar um cuidado integral e integrador, que ultrapasse a dimensão física.

\section{CONSIDERAÇÕES FINAIS}

Foi observado que a maioria dos participantes deste estudo concebem o meio ambiente como algo externo, restrito aos aspectos físicos naturais, que pode influenciar em uma atuação limitada e sem envolvimento de suas açóes/responsabilidades sobre este meio.Esta percepção reducionista do meio pode inclusive repercutir no descompromisso do cuidado consigo, com o próximo e com o planeta, dificultando o senso de responsabilidade ambiental e a redução das ações do enfermeiro.

Os resultados indicam a necessidade de ultrapassar a percepçáo reducionista, para caminhar na direçáo de pertencimento com o todo no desenvolvimento de uma consciência crítica e ativa que permita novas posturas e atitudes pró ambientais em relação ao planeta, inclusive que impactem diretamente na saúde da população.A graduaçáo de enfermagem pode e deve contribuir na ampliaçáo da percepçáo dos alunos através de um processo reflexivo e de debates constantessobre a responsabilidade socioambiental, sensibilizando-os para agir de forma responsável com o meio em que vivem, ampliando as formas de cuidadocom o meio ambiente que refletirão em um cuidado mais integral à saúde da população.

\section{REFERÊNCIAS}

BACKES M. T. S. et al.. Cuidado ecológico como um fenômeno amplo e complexo.Rev Bras Enferm. [Internet] 2011 [cited 2018 oct 03];64(5): 876. Available from: http://www.scielo.br/pdf/reben/v64n5/a12v64n5.pdf.

BARDIN, L. Análise de conteúdo. Lisboa: Edições; 2011 v. 70, p. 225, 1977. 
BRUZOS, G. A. S. et al.. Meio ambiente e enfermagem: suas interfaces e inserção no ensino de graduação. Saúde Soc. [Internet] 2011 [cited 2018oct03];20(2):462-469. Available from: <http://www.scielo.br/pdf/sausoc/v20n2/17.pdf>

CAMPONOGARA, S.; RAMOS, F. R. S; KIRCHHOF, A. L. C. A problemática ecológica na visão de trabalhadores hospitalares. Ciênc. Saúde Colet. [Internet] 2011 [cited 2017jul 26];16(8): 3561-3570. Available from:<http://www. scielosp.org/scielo.php?script=sci_arttext\&pid=S1413-81232011000900024\&lng=pt\&nrm=iso>.

CARDOSO, F. A.; FRENEDOZO, R. C; ARAÚJO M. S. T. Concepçóes de meio ambiente entre estudantes de licenciatura em ciências biológicas. Rev BEA. [Internet] 2015 [cited 2016apr 23];10(2): 95-112. Available from: http://www. sbecotur.org.br/revbea/index.php/revbea/article/viewFile/4380/3006Acesso em:

DICTORO, V. P.; GALVÃO, D. F; HANAI, F. Y. O estudo das representaçóes sociais e da percepção ambiental como instrumentos de análise das relaçóes humanas com a água. Ambiente \& Educação [Internet] 2016 [cited 2017 apr 03];21,(1):232-251. Available from:https://www.seer.furg.br/ambeduc/article/view/6078.

EVANGELISTA, J. G; FLISCH, T. M. P; PIMENTA, D. N. A formação dos agentes de combate às endemias no contexto da dengue: análise documental das políticas de saúde. Rev Eletron. Comum. Inf. Inov. Saúde. . [Internet] 2017 [cited 2018 feb 10];11(1):01-13. Available from: https:/www.reciis.icict.fiocruz.br/index.php/reciis/article/view/1219>.

KRZYSCZAK, F. R. As diferentes concepçôes de meio ambiente e suas visôes.Revista REI. [Internet] 2016 [cited 2017 apr 01];11(23):01-18. Available from: https://www.ideau.com.br/getulio/restrito/upload/revistasartigos/355_1.pdf>.

MINAYO, M. C. S. O desafio do conhecimento: pesquisa qualitativa em saúde. 10th ed. São Paulo: Hucitec; 2014.

PERES, R. R. et al.. Saúde e ambiente: (in) visibilidades e (des) continuidade na formação profissional em enfermagem. Esc. Anna Nery Rev. Enferm.. [Internet] 2016 [cited 2017 apr 13];20(1):25-32. Available from: <http://www.scielo.br/ pdf/ean/v20n1/1414-8145-ean-20-01-0025.pdf.

PERES, R. R. et al.. Percepçóes de trabalhadores e estudantes atuantes em um pronto-socorro, sobre meio ambiente e saúde. REME rev. min. Enferm. [Internet] 2014 [cited 2016 sept 13];18,(1):34-40.Available from: http://www.reme. org.br/artigo/detalhes/906.

ROMÃO, L. M. V. L; MAIA, E. R; ALBUQUERQUE, G. A. Riscos ambientais: percepção dos enfermeiros da estratégia da saúde em áreas adscritas. Rev. enferm. UERJ.[Internet] 2014 [cited 2016 sep 08];22(2):264-270. Available from: http://www.e-publicacoes.uerj.br/index.php/enfermagemuerj/article/view/13669/10459.

SILVA, R. L et al.. Concepçóes ambientais dos estudantes do curso de Licenciatura em Biologia da UFRB. Revista EA.[Internet] 2017 [cited 2017 apr 11];60. Available from: <http://www.revistaea.org/artigo.php?idartigo=2738.

YIN, R. K. Estudo de caso: planejamento e métodos. 3rd. ed. Porto Alegre: Bookman, 2005. 